7th International Symposium on Superalloy 718 and Derivatives Edited by: E.A. Ott, J.R. Groh, A. Banik, I. Dempster, T.P. Gabb, R. Helmink, X. Liu, A. Mitchell, G.P. Sjöberg, and A. Wusatowska-Sarnek

\title{
NUMERICAL SIMULATION OF HOT DIE FORGING FOR
}

\author{
IN 718 DISC \\ X.D. $\mathrm{Lu}^{1}$, J.H. Du ${ }^{1}$, Q. Deng ${ }^{1}$, G.S. Chen ${ }^{2}$, X.F. Liu $^{3}$ \\ ${ }^{1}$ Department of superalloy, Central Iron \& Steel Research Institute, Beijing, 100081, \\ China \\ ${ }^{2}$ Special Steel Company, Bao Steel Group, Shanghai, 200940, China \\ ${ }^{3}$ Advanced Manufacture Center, Central Machine Science Research Institute, Beijing, \\ 100083, China
}

Keywords: Hot die forging, Numerical Simulation, IN 718, Disc

\begin{abstract}
Continuous improvements of properties for individual parts are indispensable for perpetual development of aircraft engines. Concerning turbine disc, numerical simulation of forging process is one of the most attractive tools to reduce the cost and time and to improve the properties and the reliability at the same time. In this paper, the hot deformation behavior of IN 718 superalloy has been characterized in the temperature range $900-1020{ }^{\circ} \mathrm{C}$ and strain rate range $0.001-0.1 \mathrm{~s}^{-1}$ using isothermal constant strain rate compression tests on process annealed material, with a view to obtain a correlation between grain size and the process parameters. Through a comparison study of two forging methods, temperature-field and strain-field finite element analysis modeling were established, and load-time curves were obtained for a turbine disc under routine and hot die forging process conditions. Results of numerical simulation show that compared to routine forging, hot die forging gives a decrease in total forging force, the temperature-field and strain-field of the turbine disc is more uniform. The effect of cold die on the microstructure is decreased notably under hot die forging condition.
\end{abstract}

\section{Introduction}

IN 718 belongs to a class of nickel-iron base superalloys with a face-centered cubic (FCC) austenitic matrix that is strengthened by precipitation of an ordered body centered tetragonal (BCT) intermetallic precipitate $\gamma^{\prime \prime}$. The alloying of nickel and iron results in the formation of the austenitic matrix, $\gamma$, while the addition of chromium and molybdenum cause solid solution strengthening. Also, alloying with niobium causes precipitation of 
the metastable hardening constituent $\gamma^{\prime \prime}\left(\mathrm{Ni}_{3}(\mathrm{Nb}, \mathrm{Ti})\right)[1-3]$. The properties of IN 718 are attributed to the combined effects of the chemistry, heat treatment, and microstructure. The chemistry is tailored not only for solid solution strengthening but also for precipitation hardening developed during heat treatment, which combined with a fine grained microstructure lead to excellent mechanical properties such as low cycle fatigue resistance and elevated temperature strength [4-5]. The properties of a gas turbine disc are sensitive to the microstructure, in particular the grain size, which is dependent on the processing history. The ability to precisely control the microstructure development during forging is dependent on controlling the thermomechanical process so that the work piece is deformed within a safe region where no microstructural damage due to flow instabilities occur.

In this paper, the hot deformation behavior of IN 718 under different deformation conditions, including the flow stress and associated microstructural evolution, was systematically studied by hot compression tests. The dependence of flow behavior and microstructural evolution on deformation temperature and strain rate was established by introducing the Zener-Hollomon parameter. Temperature and strain-fields for both the routine forging and hot die forging processes were established by finite element analysis using Deform-2D software.

\section{Experimental Procedure}

The chemical composition (wt.\%) of the Ni-based superalloy IN 718 used in this study are as follows: Cr, 18.09; Fe, 17.69; Nb, 5.43; Mo, 3.07; Ti, 0.97; Al, 0.46; Co, 0.18; Si, 0.078; $\mathrm{Mn}, 0.065 ; \mathrm{Cu}, 0.065 ; \mathrm{C}, 0.040 ; \mathrm{S}<0.001 ; \mathrm{P}<0.007 ; \mathrm{Ni}$, balance. Hot compression tests were conducted using a MTS 810.13 simulator at temperature of 900 ${ }^{\circ} \mathrm{C}, 940{ }^{\circ} \mathrm{C}, 980{ }^{\circ} \mathrm{C}$ and $1020{ }^{\circ} \mathrm{C}$ and in the strain rate range of $0.001,0.005,0.01,0.05$ and $0.1 \mathrm{~s}^{-1}$ with $20 \mathrm{~mm}$ diameter, $30 \mathrm{~mm}$ high cylindrical specimens. All specimens were quickly heated to the hot compression temperature and held for $30 \mathrm{~min}$ and then deformed to a strain of 0.7 and immediately water cooled to room temperature. The deformed specimens were sectioned parallel to the compression axis and prepared for microstructure observation. The load-stroke data obtained in compression were processed to obtain true stress-true strain curves using the standard method.

Metallography of the tested specimens was performed to study the effect of deformation parameters, i.e. temperature and strain-rate, on the microstructure. The as-received material and tested specimens were prepared for optical microscopy using standard metallographic techniques of sectioning, mounting, coarse and fine grinding, final polishing, and etching. The specimens were immersion etched with $50 \mathrm{ml} \mathrm{H}_{2} \mathrm{O}+50$ 
$\mathrm{ml} \mathrm{HCl}+50 \mathrm{ml} \mathrm{HF}+3 \mathrm{ml} \mathrm{H} \mathrm{O}_{2}$ to reveal the microstructure. Microstructure was evaluated with LEICA MEF4-A type optical microstructure (OM). Quantitative analysis of the as deformed specimens was performed to determine the average recrystallized grain size. The average recrystallized grain size was determined using the line intercept method.

\section{Results and Discussion}

\section{$\underline{\text { True stress-True strain curves and constitutive relationship of IN } 718}$}

True stress-True strain curves. The load versus time curves generated from the isothermal compression tests were used to calculate the true stress versus true strain curves. A series of typical stress-strain curves of the Ni-based superalloy deformed at various temperature from 900 to $1020^{\circ} \mathrm{C}$ under strain rates from 0.001 to $0.1 \mathrm{~s}^{-1}$ is shown in Fig. 1 . A set of representative true stress versus true strain curves obtained at $980{ }^{\circ} \mathrm{C}$ is shown in Fig. 1(c). The flow behavior is similar for all test conditions. Following initial work hardening leading to a peak in the flow stress at a critical strain, the flow curves exhibit flow softening followed by steady state flow at larger strains. However at the highest strain rate, the flow curves exhibit continuous flow softening.
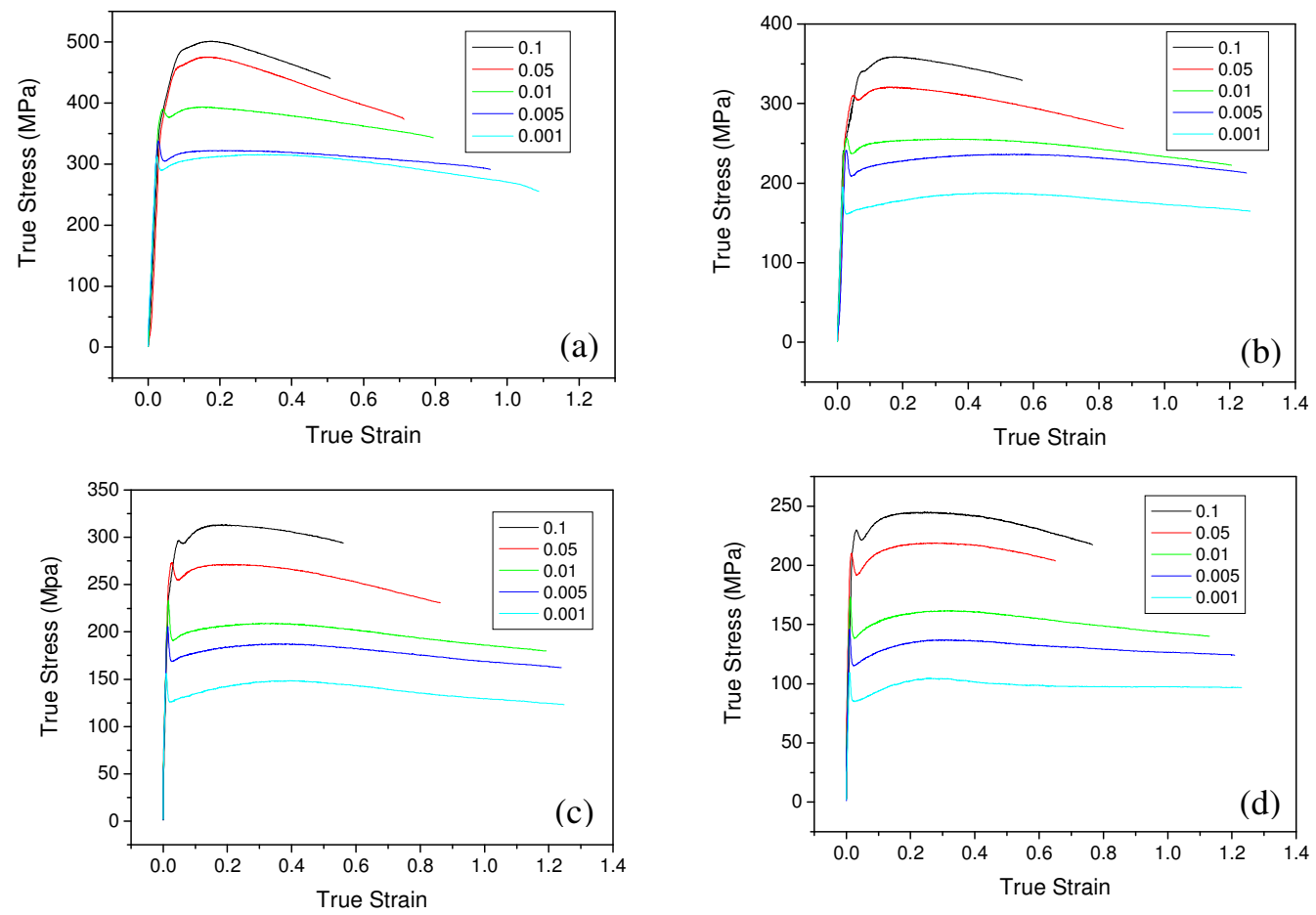

Fig. 1 True stress-true strain curves of $\mathrm{IN} 718$ at $900^{\circ} \mathrm{C}(\mathrm{a}), 940^{\circ} \mathrm{C}(\mathrm{b}) 980^{\circ} \mathrm{C}(\mathrm{c})$ and $1020^{\circ} \mathrm{C}(\mathrm{d})$.

It can be seen that the flow stress increases to a peak value with increasing strain and then 
decreases as the strain is further increased. The initial rapid rise in stress is associated with an increase in dislocation density and the formation of poorly developed sub-grain boundaries, as a result of work hardening and dynamic recovery. In alloys with low or intermediate stacking fault energy, dynamic recovery proceeds slowly. The high dislocation density stimulates the occurrence of dynamic recrystallization once a critical strain is exceeded. The flow stress increases with increasing strain rate and decreasing temperature. These results are in good agreement with previous reports dealing with high temperature compressive behavior of IN 718[4-6].

Constitutive relationship of IN 718. Constant strain rate flow curves have been analyzed in order to develop a constitutive model to describe the high temperature behavior of this materials using the standard kinetic rate equation that relates the steady state flow stress $(\sigma)$ to the test temperature $(\mathrm{T})$ and the strain rate $(\dot{\varepsilon})$ given by:

$$
\dot{\varepsilon}=\mathrm{A} \sigma^{\mathrm{n}} \exp (-\mathrm{Q} / \mathrm{RT})
$$

Where $\sigma$ is the flow stress, $\mathrm{n}$ is the stress exponent, $\mathrm{Q}$ is the activation energy, and $\mathrm{A}$ is a constant. For this model, steady state flow stress $(\sigma)$ values at different temperatures $(\mathrm{T})$ and strain rates $(\dot{\varepsilon})$ at a true strain of 0.5 have been used.

A plot of $\log (\sigma)$ vs. $\log (\dot{\varepsilon})$ for different temperatures is shown in Fig. 2. It can be seen from this plot that the dependence of flow stress on strain rate is non-linear over the entire range of temperatures and strain rates tested. The stress exponent, $\mathrm{n}$, defined by:

$$
\mathrm{n}=\left.\frac{\partial(\log \mathcal{E})}{\partial(\log \sigma)}\right|_{\mathrm{T}, \varepsilon}
$$




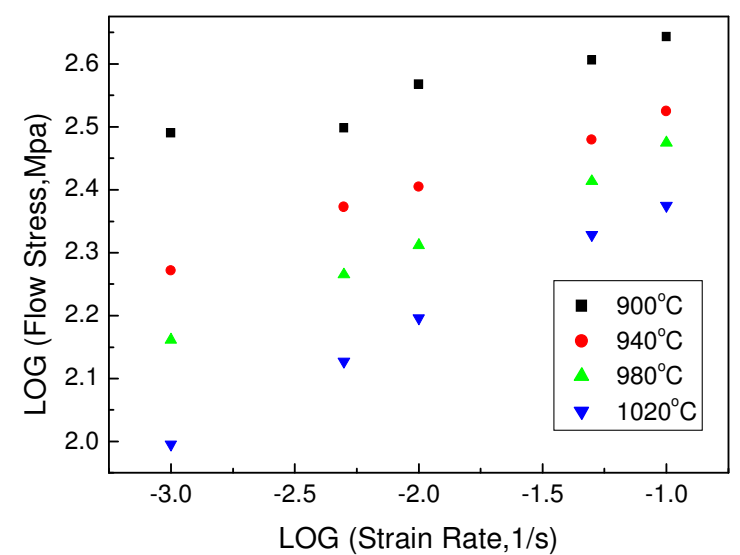

Fig. 2 Variation of the flow stress with strain rate for different test temperature.

Is strain rate dependent and hence the kinetic rate is not valid in the full range of process parameters. However, over a narrow range of temperature bounded by the $940-1020{ }^{\circ} \mathrm{C}$ and limited range of strain rates $\left(0.005-0.1 \mathrm{~s}^{-1}\right)$ a liner fit a good approximation and the value of $\mathrm{n}$ is found to be 6.17 .

The activation energy Q, may be defined by:

$$
\mathrm{Q}=\left.\mathrm{nR} \frac{[\partial \ln (\sigma)]}{[\partial(1 / \mathrm{T})]}\right|_{\dot{\varepsilon}}
$$

and is computed from the slopes of the plot shown in Fig. 3. If the slopes are computed within the same temperature range as mentioned before, the apparent activation energy is approximately $528 \mathrm{~kJ} / \mathrm{mol}$. Compared to the previously reported value, for example, 443 $\mathrm{kJ} / \mathrm{mol}$ by H.Yuan et al. [6], $443.2 \mathrm{~kJ} / \mathrm{mol}$ by Y. Wang et al. [7], $400 \mathrm{~kJ} / \mathrm{mol}$ by S.C. Medeiros et al. [8], $423 \mathrm{~kJ} / \mathrm{mol}$ by M.J. Weis et al. [9], activation energy Q in this study is appreciably high, due to the different original microstructure of compress samples. It should be noted from the figure that the scatter increases with increasing strain rate. This would imply that as strain rate is increased the mechanism responsible for deformation is changing.

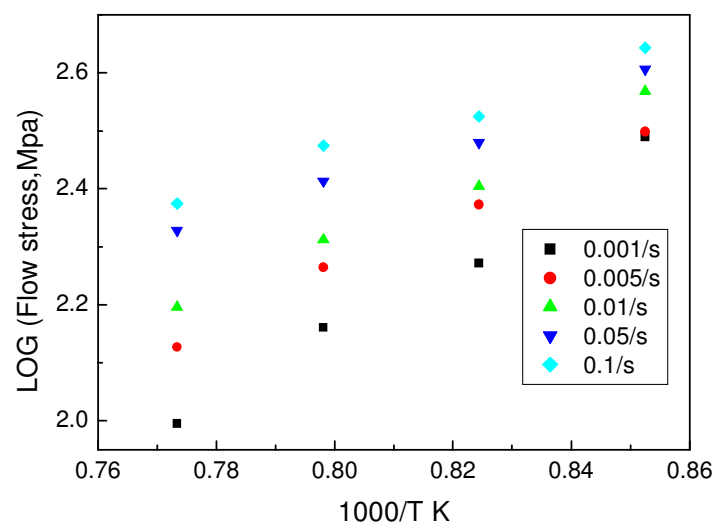

Fig. 3 Variation of the flow stress with temperature for different strain rate. 
The above value of apparent activation energy was used to calculate the Zener-Hollomon parameter $(\mathrm{Z})$ defined by:

$$
\mathrm{Z}=\dot{\varepsilon} \exp (\mathrm{Q} / \mathrm{RT})
$$

and is plotted versus the flow stress in Fig. 4. This plot shows a good correlation between the flow stress and the Zener-Hollomon parameter which implies that the flow stress follows the expected trend with respect to strain rate and temperature. It also implies that within the temperature range bounded by the $940-1020{ }^{\circ} \mathrm{C}$, the power law relationship for hot deformation is may be applied. In a word, Constitutive relationship of IN 718 as follows:

$$
\dot{\varepsilon}=1.58 \times 10^{18} \sigma^{6.17} \exp (-528000 / \mathrm{RT})
$$

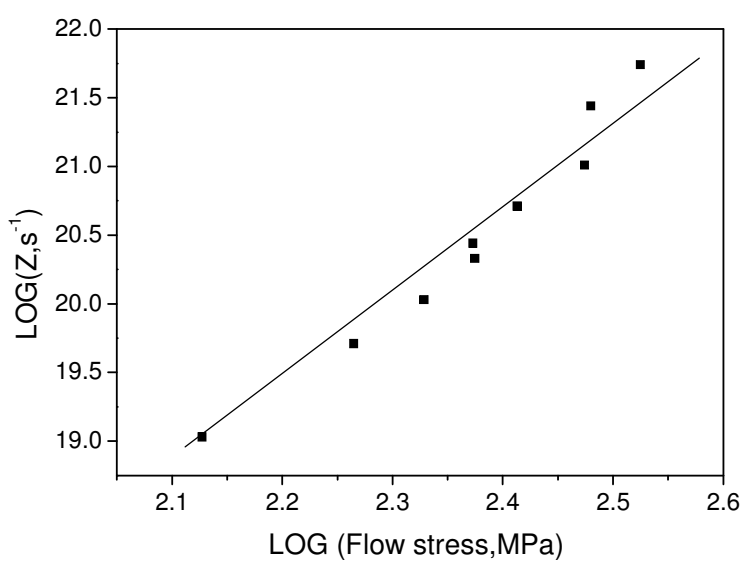

Fig. 4 Variation of the $\mathrm{Z}$ parameter with flow stress.

Numerical simulation of hot die forging for IN 718 disc

Basic parameters of forging processing.

\begin{tabular}{lcc}
\hline & routine forging & hot die forging \\
\hline forging temperature & $1010-930^{\circ} \mathrm{C}$ & $1010-930^{\circ} \mathrm{C}$ \\
\hline die materials & $5 \mathrm{CrNiMo}$ & $\mathrm{K} 3$ \\
\hline die temperature & $450{ }^{\circ} \mathrm{C}$ & $900^{\circ} \mathrm{C}$ \\
\hline ram velocity & $3.8 \mathrm{~mm} / \mathrm{s}$ & $3 \mathrm{~mm} / \mathrm{s}$ before holding \\
\hline friction coefficient & 0.08 & 0.08 \\
\hline
\end{tabular}

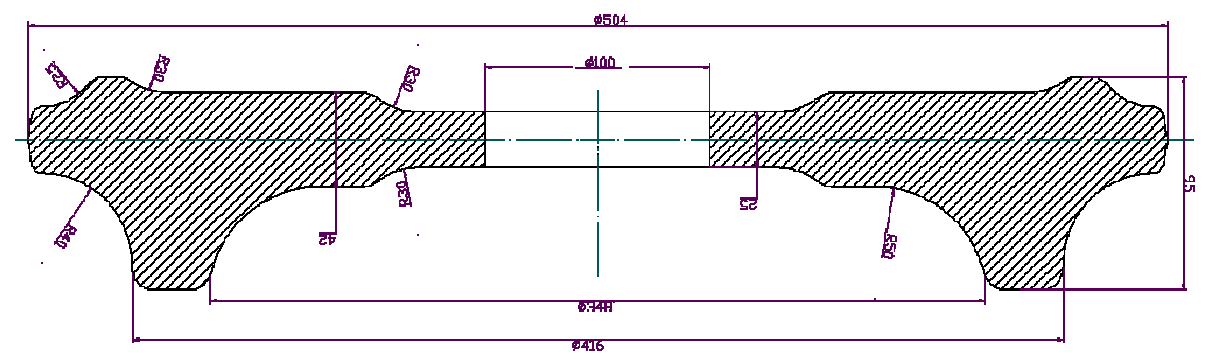


Forging figure of IN 718 disc as follows:

Results of numerical simulation. Under hot die forging condition, the temperature-field in the IN 718 disc at the end of the forging stroke is in the range $945 \sim 1024^{\circ} \mathrm{C}$, as shown in Fig. 5(b). The of the majority of the disc is below initial forging temperature $1010{ }^{\circ} \mathrm{C}$, except in the disc center. Whereas under routine forging condition, the temperature-field in the IN 718 disc shows a range of $980 \sim 1060^{\circ} \mathrm{C}$. At the center of disc the temperature is $1060{ }^{\circ} \mathrm{C}$, an increase of $50{ }^{\circ} \mathrm{C}$ over the initial forging temperature, as shown in Fig. 5(a).

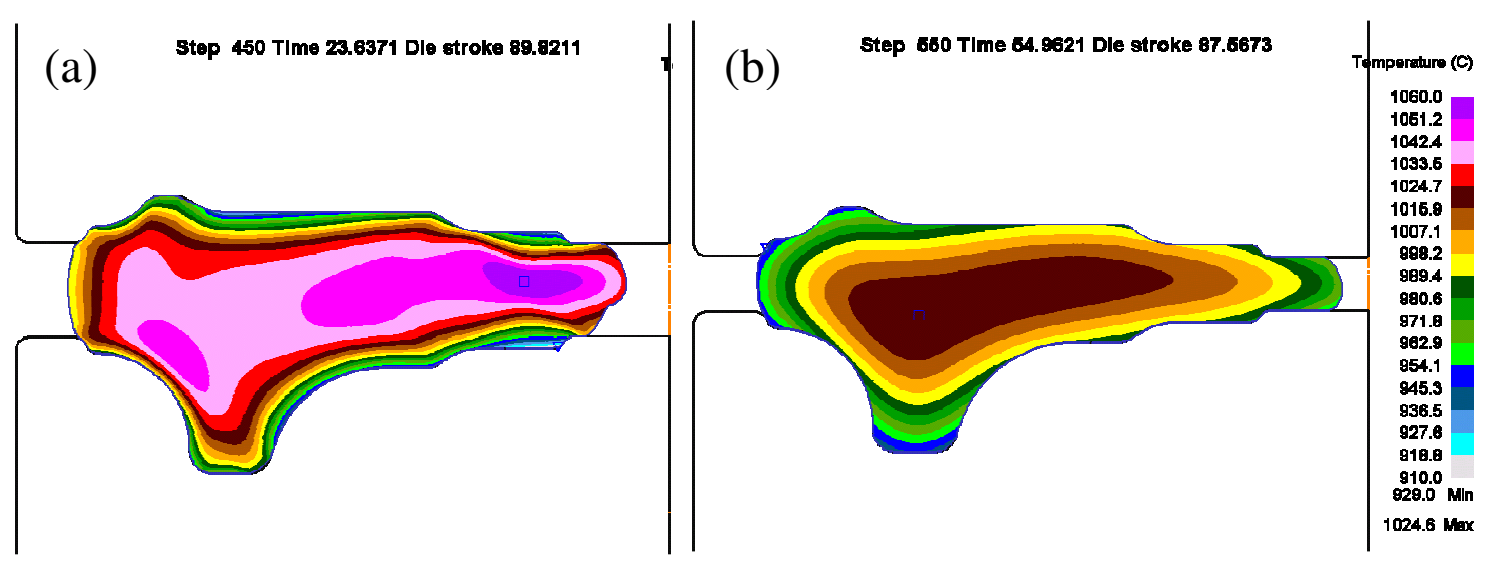

Fig. 5 Comparison analyses of temperature-filed under routine forging (a) and hot die forging (b) conditions

Under hot die forging condition, strain-field in the IN 718 disc at finished forging is bounded of 0.35 2.49, as shown in Fig. 6(b). Change range of stain-field in the noumenon position of the disc is between 0.52 and 1.50. Stain-field in the installation position is bounded of $0.19 \sim 0.52$. Center position with the maximal strain is 2.98 was moved by mechanical processing.

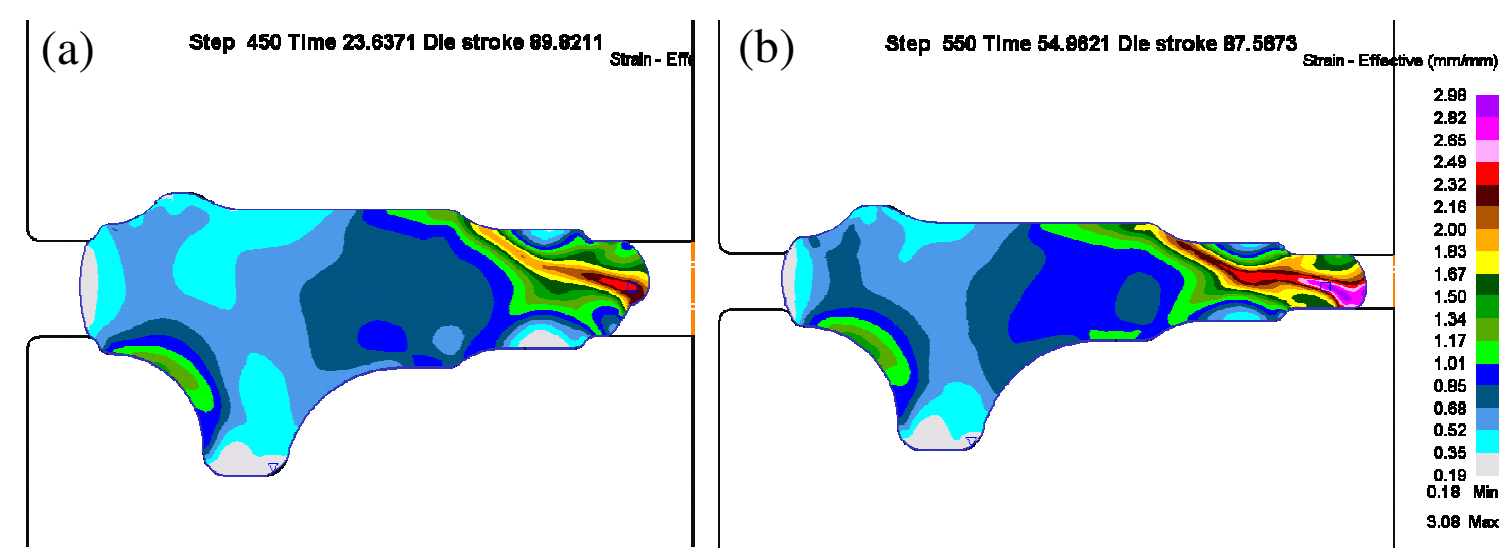


Fig. 6 Comparison analyses of strain-filed under routine forging (a) and hot die forging (b) conditions

According to the metallographic observation of dynamic recrystallization for the IN 718 under different temperature, strain rate and strain conditions, as shown in Fig. 7, nearly full dynamic recrystallization was occurred at noumenon position of the disc under hot die forging and average grain size is approximately $20 \mu \mathrm{m}$. For the routine forging condition the dynamically recrystallised grains have undergone growth because of temperature rise from deformation heat.
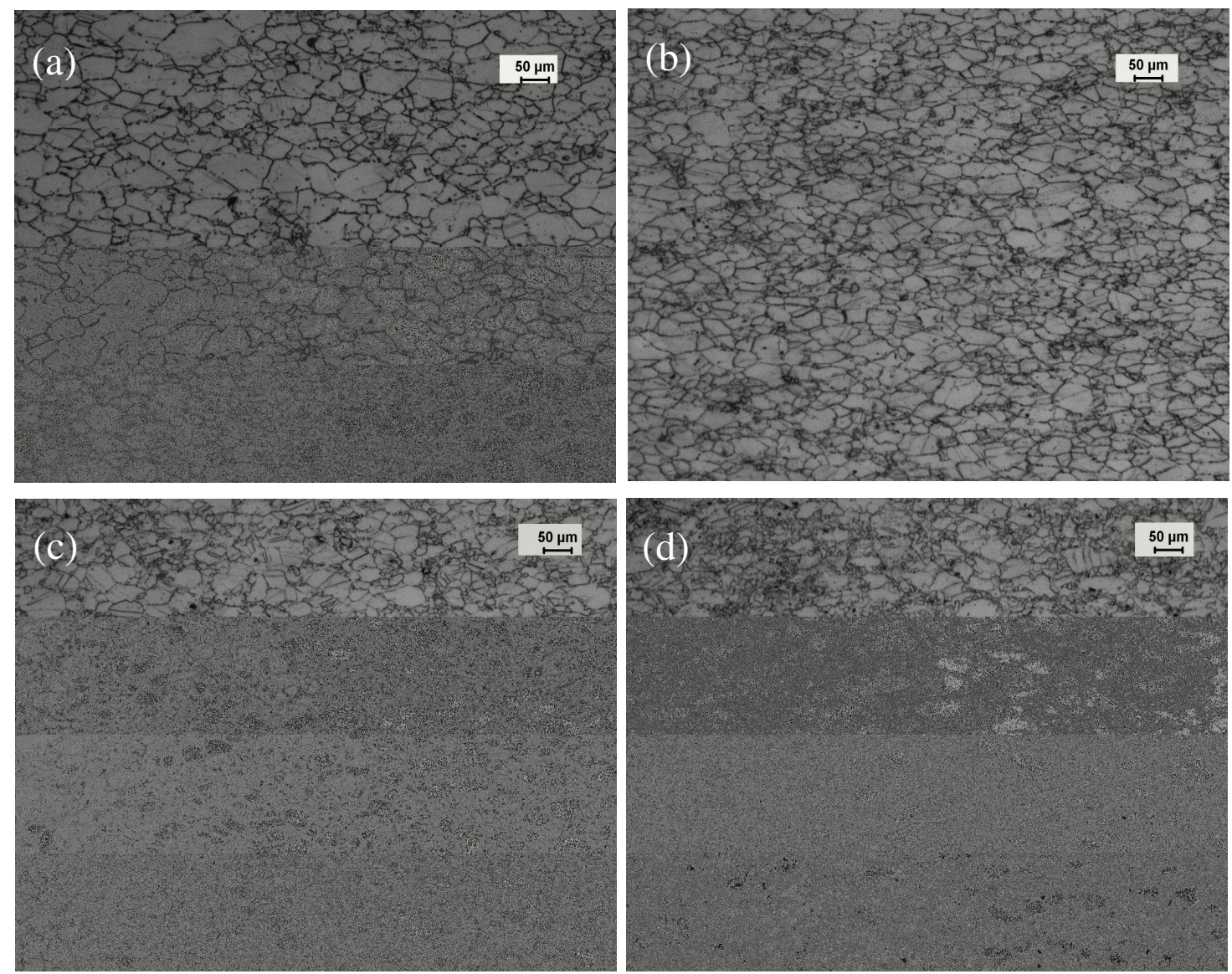

Fig. 7 Dynamic recrystallization occurring after compression tests at: (a) $940{ }^{\circ} \mathrm{C}$, $0.05 \mathrm{~S}^{-1}, 30 \%$; (b) $940{ }^{\circ} \mathrm{C}, 0.05 \mathrm{~S}^{-1}, 40 \%$; (c) $980{ }^{\circ} \mathrm{C}, 0.05 \mathrm{~S}^{-1}, 30 \%$;(d) $980{ }^{\circ} \mathrm{C}, 0.05 \mathrm{~S}^{-1}$, $40 \%$.

Under hot die forging condition, stress-field in the IN 718 disc at finished forging is in the range 54 274MPa, as shown in Fig. 8(b). The routine forging condition, the stress-field Fig. 8 (a) is in the range $78 \sim 410 \mathrm{MPa}$. Therefore, die material is subject to higher, deformation forces under routine forging. As shown in Fig. 9 shows the 
load-stroke predictions for hot die forging condition, with a peak load of $55 \mathrm{MN}$, significantly lower than the routine forging peak load of 143MN.
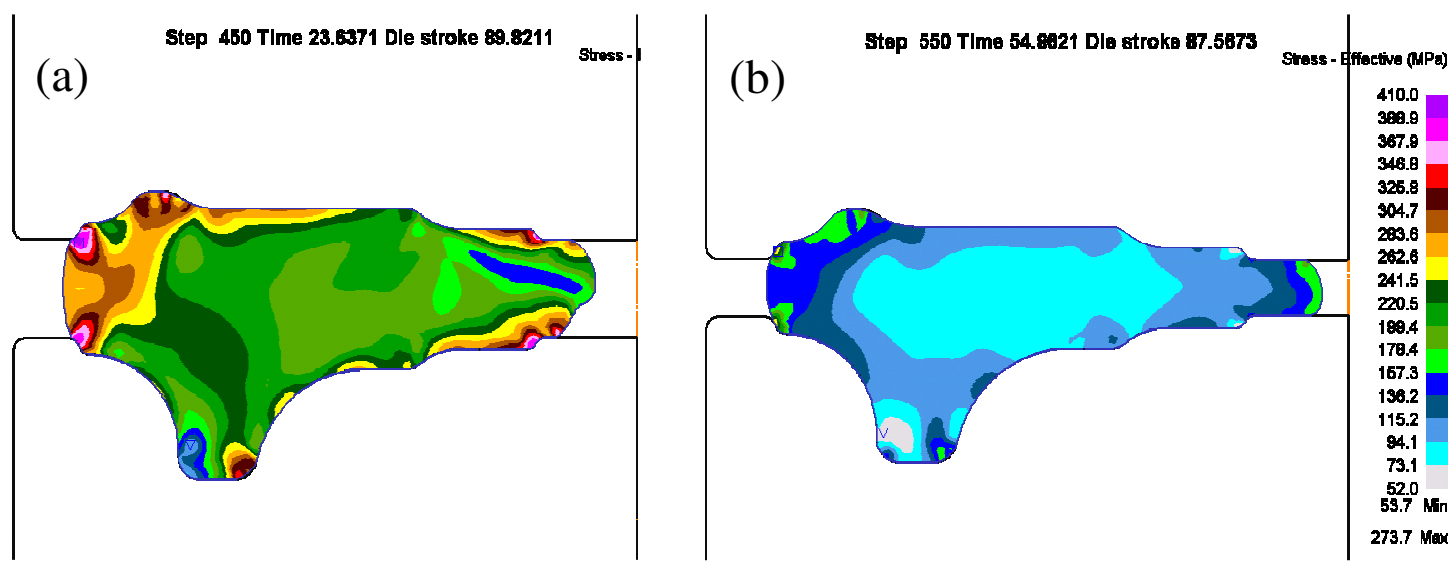

Fig. 8 Comparison analyses of stress-filed under routine forging (a) and hot die forging (b) conditions

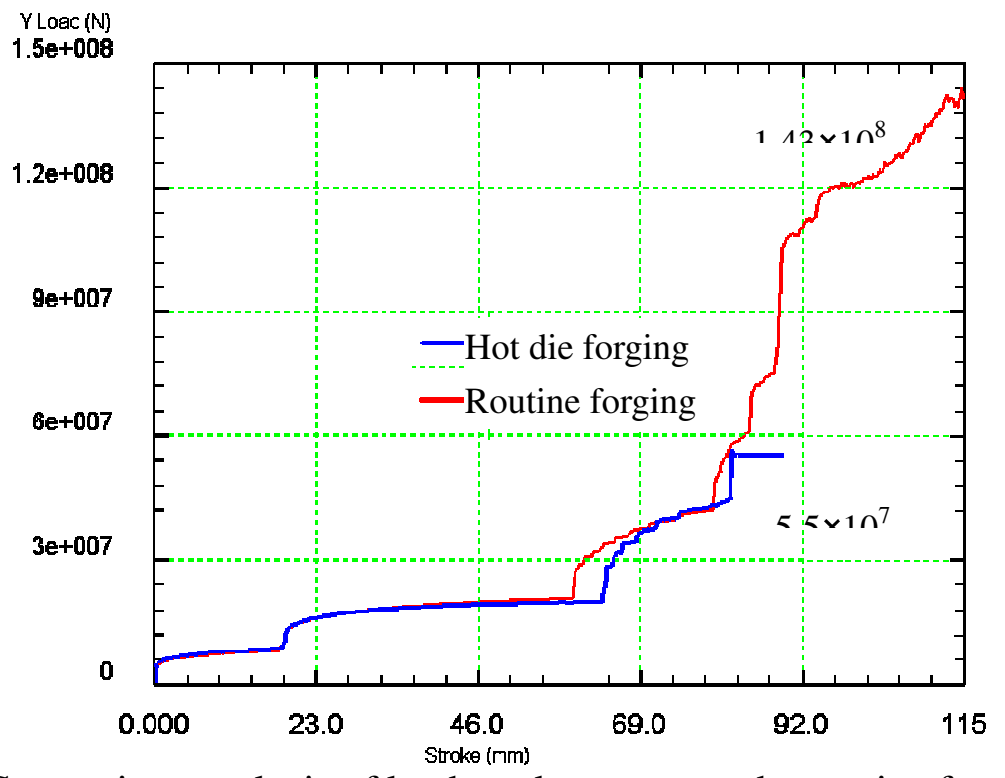

Fig. 9 Comparison analysis of load-stroke curves under routine forging and hot die forging conditions

\section{Conclusions}

1. Within the temperature range bounded by the $940-1020{ }^{\circ} \mathrm{C}$, and strain rate range 
bounded by the $0.005-0.1 \mathrm{~s}^{-1}$, the power law relationship for hot deformation of IN 718 may be applied. The constitutive relationship of IN 718 as follows:

$$
\dot{\varepsilon}=1.58 \times 10^{18} \sigma^{6.17} \exp (-528000 / \mathrm{RT})
$$

2. Compare to routine forging, total load of forging is decreased effectively, temperature-field and strain-field of turbine disc is much uniformly, average size of recrystallization grain is little, effect of cold die on the microstructure is decreased notably under hot die forging condition.

\section{Acknowledgment}

The research was supported by National Important Base Research and Development Program of China. (Contract No. 2010CB631203).

\section{References}

1. Dayong Cai, Weihong Zhang, Pulin Nie, Wenchang Liu, Mei Yao. Dissolution kinetics of $\delta$ phase and its influence on the notch sensitivity of Inconel 718. Materials Characterization, 58 (2007) 220-225.

2. Saied Azadian, Liu Ying Wei, Richard Warren. Delta phase precipitation in Inconel 718. Materials Characterization, 53 (2004) 7-16.

3. A. Thomas, M. EI-Wahabi, J.M. Cabrera, J.M. Prado. High temperature deformation of Inconel 718. Journal of Materials Processing Technology, 177 (2006) 469-472.

4. J.M. Zhang, Z.Y. Gao, J.Y. Zhuang, Z.Y. Zhong, P. Janschek. Strain-rate hardening behavior of superalloy IN 718. Journal of Materials Processing Technology 70 (1997) 252-257.

5. S.C. Medeiros, Y.V.R.K. Prasad, W.G. Frazier, R. Srinivasan. Modeling grain size during hot deformation of IN 718. Scripta Materialia 42 (2000) 17-23.

6. H. Yuan, W.C. Liu. Effect of the $\delta$ phase on the hot deformation behavior of Inconel 718. Materials Science and Engineering A, 408 (2005) 281-289.

7. Y. Wang, W.Z. Shao, L. Zhen, L. Yang, X.M. Zhang. Flow behavior and microstructures of superalloy 718 during high temperature deformation. Materials 
Science and Engineering A, 497 (2008) 479-486.

8. S.C. Medeiros, Y.V.R.K. Prasad, W.G. Frazier, R. Srinivasan. Microstructural modeling of metadynamic recrystallization in hot working of IN 718 superalloy. Materials Science and Engineering A, 293 (2000) 198-207.

9. M.J. Weis, M.C. Mataya, S.W. Thompson. In: E.A. Loria (Ed.). Superalloys 718, TMS, 1989, 135-141. 